\title{
PROSES MINING UNTUK OPTIMASI PROSES BISNIS
}

\author{
Nur Fitrianti Fahrudin \\ Program Studi Sistem Informasi \\ Institut Teknologi Nasional Bandung \\ Jl. PH.H. Mustofa No.23, Kota Bandung, Jawa Barat 40124 \\ nurfitrianti@itenas.ac.id
}

\begin{abstract}
Abstrak
Organisasi saat ini perlu melakukan analisis terhadap proses bisnis mereka dalam rangka meningkatkan kinerja serta produktifitas bisnis. Selain itu analisis ini dapat menjadi suatu cara untuk bersaing dengan kompetitor. Akan tetapi analisis proses bisnis ini jika dilakukan secara manual membutuhkan waktu yang cukup banyak. Hal yang dapat dilakukan untuk mengatasi permasalahan ini adalah dengan melakukan proses mining. Sistem Informasi yang dimiliki oleh sebuah perusahaan tentunya menyimpan setiap aktifitas bisnis mereka. Data yang tersimpan ini dapat diolah untuk menemukan proses bisnis yang terjadi. Data ini biasa disebut event log. Event log membantu organisasi untuk menemukan kesenjangan diantara antara proses bisnis yang terjadi dengan yang diharapkan. Berdasarkan kesenjangan inilah nantinya proses bisnis dapat dievaluasi untuk kemudian diperbaiki.
\end{abstract}

Kata kunci :

Proses mining, event log, proses bisnis

\begin{abstract}
Organizations currently need to conduct an analysis of their business processes in order to improve business performance and productivity. In addition, this analysis can be a way to compete with competitors. However, the analysis of this business process if done manually requires considerable time. Process mining is a technique that helps solve this problem. Information systems that are owned by a company certainly store their every business activity. This data can be processed to find business processes that occur. This data is usually called an event log. Event logs help organizations to find gaps between business processes that occur with those expected. Based on this gap business processes can later be evaluated for later improvement.
\end{abstract}

Keywords :

Process Mining, event logs, business processes

\section{Pendahuluan}

Saat ini perubahan lingkungan sering sekali terjadi, seperti beragamnya permintaan konsumen, hadirnya produk-produk baru dan pesaing baru (Gemini, 2007). Hal ini menyebabkan organisasi perlu dengan segera mencari peluang bisnis dan menerapkan ide strategis baru (Wang, Pan, Yang, \& Chou, 2011). P. Weill, Kepala Pusat Riset Sistem Informasi di Massachusetts Institute of Technology (MIT), mengatakan bahwa "Dalam era globalisasi, kemampuan untuk memenuhi harapan dari konsumen adalah inti dari profitabilitas. Jika perusahaan tidak tangkas, perusahaan tidak akan dapat memenuhi harapan dari konsumen, karena harapan konsumen tidak pernah statis" (Gemini, 2007). Selain itu perusahaan juga perlu memperhatikan kualitas dari produk atau layanan yang mereka berikan untuk memastikan konsistensinya (Rose, 2005).

Menyadari faktor penting dalam lingkungan yang berubah dengan cepat saat ini, banyak organisasi telah berusaha untuk mencapai ketangkasan perusahaan melalui berbagai inisiatif, seperti riset pasar yang mendalam, integrasi informasi, dan implementasi strategi baru (Wang et al., 2011). Banyak perusahaan juga berlomba-lomba untuk mengadaptasi atau berinvestasi teknologi baru demi meningkatkan kinerja dan produktivitas mereka. Pengembangan teknologi informasi memang penting mengingat terdapat lingkungan bisnis yang memerlukan perbaikan terus-menerus dimana tujuan utama bisnis selalu menjadi sasaran yang harus dicapai oleh perusahaan, walau pada praktiknya tujuan utama ini tidak pernah benar-benar tercapai (Daniel Minoli, 2008). Akan tetapi investasi terhadap teknologi informasi ini, membutuhkan biaya yang cukup besar. 
Selain itu, mengadaptasi teknologi yang baru ini belum tentu juga dapat menyelesaikan berbagai permasalahan yang ada (Kenneth C. Laudon \& Jane P. Laudon, 2013).

Melakukan analisis terhadap proses bisnis yang ada pada perusahaan saat ini, merupakan salah satu langkah yang dapat dilakukan. Hal ini dikarenakan proses bisnis sebuah perusahaan dapat menjadi sumber kekuatan kompetitif, yang dapat membuat perusahaan beroperasi serta berinovasi lebih baik (Kenneth C. Laudon \& Jane P. Laudon, 2013). Selain itu,koordinasi dan perancangan proses bisnis yang baik menjadi tolak ukur kinerja sebuah perusahaan (Kenneth C. Laudon \& Jane P. Laudon, 2013). Untuk mendukung proses bisnis atau proses operasional harian, sebuah perusahaan pada umumnya memiliki Sistem Informasi.

Pada umumnya sistem informasi ini, memiliki riwayat yang didalamnya berisi proses yang telah dieksekusi. Jika dikategorikan, riwayat ini dapat menggambarkan suatu proses bisnis yang terjadi pada rentan waktu tertentu. Kumpulan dari riwayat ini biasa disebut dengan catatan peristiwa (event log). Dengan adanya event log memungkinkan perusahaan untuk melakukan pemodelan, analisis dan evaluasi terhadap proses bisnis yang dijalankan, dimana hal ini merupakan sebagai bagian dari siklus manajemen proses bisnis (W. van der Aalst, 2016). Tujuan utama dari proses mining adalah mengekstraksi informasi yang bermanfaat dari event log yang merekam aktivitas yang dilakukan organisasi (Veiga \& Ferreira, 2010).

\section{KAJIAN LITERATUR}

Bab ini memuat landasan teori atau ulasan singkat teori mengenai proses mining, event log dan notasi proses bisnis menggunakan petri net.

\section{II.1 Proses Mining}

Proses mining merupakan suatu penelitian yang masih tergolong baru yang menggabungkan antara mesin learning dan data mining di satu sisi serta pemodelan proses dan analisis disisi lainnya (W. M. P. van der Aalst, 2016a). Ide dari proses mining adalah untuk discover, conformance checking dan enhancment, dengan mengekstraksi pengetahuan dari event log yang tersedia dalam sebuah sistem (Vossen, 2012). Gambar 1 menunjukan tiga tipe dari proses mining.
Proses discovery adalah tipe pertama dalam proses mining. Teknik ini akan membuat suatu model berdasarkan event log yang berasal dari sistem informasi dimana informasi yang digunakan tidak bersifat apriori (asumsi) (W. M. P. van der Aalst, 2016b).

Tipe kedua adalah conformance checking. Teknik ini menggabungkan antara model proses yang ada dengan event log dari proses yang sama. Conformance checking dapat digunakan untuk memeriksa apakah kejadian nyata yang terjadi sesuai dengan model yang ada dan sebalikanya (W. M. P. van der Aalst, 2016b). Teknik ini relevan untuk audit dan menjaga keselarasan bisnis, sebagai contoh event log dapat menelusuri model proses bisnis menggunakan teknik replay untuk menemukan penyimpangan yang tidak diinginkan yang menunjukan inefisiensi (W. M. P. van der Aalst, 2011). Selain itu teknik ini juga dapat digunakan untuk mengukur kinerja algoritma proses discovery dan untuk memperbaiki model yang tidak sesuai dengan kenyataan.

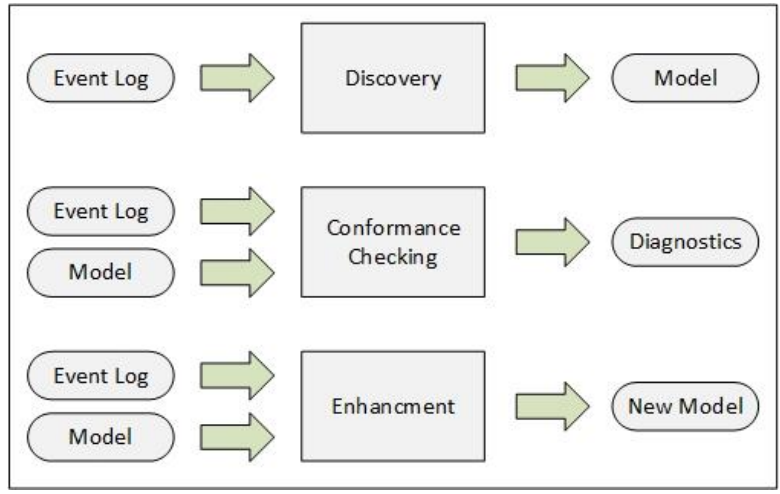

Gambar 1. Tiga tipe dasar dari proses mining dijelaskan dari segi input dan output (sumber: (W.M.P Van der Aalst dkk., 2012))

Tipe ketiga adalah enhancement, dimana idenya adalah memperluas atau memperbaiki model proses yang ada menggunakan informasi yang didapat dari proses aktual yang terdapat dalam event log (W. M. P. van der Aalst, 2016b). Tipe conformance checking memastikan keselarasan antara model dengan realita, sedangkan tipe ketiga ini bertujuan untuk merubah atau menambah model yang ada.

Salah satu tools yang biasa digunakan untuk mendukung proses mining adalah ProM. 


\section{II.2 Event Log}

Event log adalah sebuah historikal transaksi yang tersimpan dalam sebuah sistem informasi. Event log ini berisi beberapa event untuk suatu case tertentu. Event log yang tersimpan dalam sebuah sistem informasi ini dapat dianalisa menggunakan proses mining. Untuk melakukan analisa menggunakan proses mining sebuah event log membutuhkan setidaknya informasi yang cukup seperti aktifitas yang dapat menjelaskan sebuah kejadian beserta waktu terjadinya (Suriadi, Andrews, ter Hofstede, \& Wynn, 2017). Sumber data atau log peristiwa ini dapat diperoleh dari berbagai sumber seperti flat file, excel spreadsheet, log transaksi atau basis data (W. M. P. van der Aalst, 2011).

\begin{tabular}{|c|c|c|c|c|c|c|}
\hline \multirow[t]{2}{*}{ case id } & \multirow[t]{2}{*}{ event id } & \multicolumn{5}{|c|}{ properties } \\
\hline & & timestamp & activity & resource & cost & $\ldots$ \\
\hline \multirow{5}{*}{1} & 35654423 & $30-12-2010: 11.02$ & register request & Pete & 50 & $\ldots$ \\
\hline & 35654424 & $31-12-2010: 10.06$ & examine thoroughly & Sue & 400 & $\ldots$ \\
\hline & 35654425 & $05-01-2011: 15.12$ & check ticket & Mike & 100 & $\ldots$ \\
\hline & 35654426 & $06-01-2011: 11.18$ & decide & Sara & 200 & $\ldots$ \\
\hline & 35654427 & 07-01-2011:14.24 & reject request & Pete & 200 & $\ldots$ \\
\hline \multirow{5}{*}{2} & 35654483 & $30-12-2010: 11.32$ & register request & Mike & 50 & $\ldots$ \\
\hline & 35654485 & $30-12-2010: 12.12$ & check ticket & Mike & 100 & $\ldots$ \\
\hline & 35654487 & $30-12-2010: 14.16$ & examine casually & Pete & 400 & $\ldots$ \\
\hline & 35654488 & $05-01-2011: 11.22$ & decide & Sara & 200 & $\ldots$ \\
\hline & 35654489 & 08-01-2011:12.05 & pay compensation & Ellen & 200 & $\ldots$ \\
\hline \multirow{9}{*}{3} & 35654521 & $30-12-2010: 14.32$ & register request & Pete & 50 & $\ldots$ \\
\hline & 35654522 & $30-12-2010: 15.06$ & examine casually & Mike & 400 & $\ldots$ \\
\hline & 35654524 & 30-12-2010: 16.34 & check ticket & Ellen & 100 & $\ldots$ \\
\hline & 35654525 & $06-01-2011: 09.18$ & decide & Sara & 200 & $\ldots$ \\
\hline & 35654526 & $06-01-2011: 12.18$ & reinitiate request & Sara & 200 & $\ldots$ \\
\hline & 35654527 & $06-01-2011: 13.06$ & examine thoroughly & Sean & 400 & $\ldots$ \\
\hline & 35654530 & 08-01-2011:11.43 & check ticket & Pete & 100 & $\ldots$ \\
\hline & 35654531 & 09-01-2011:09.55 & decide & Sara & 200 & $\ldots$ \\
\hline & 35654533 & 15-01-2011:10.45 & pay compensation & Ellen & 200 & $\ldots$ \\
\hline \multirow{5}{*}{4} & 35654641 & $06-01-2011: 15.02$ & register request & Pete & 50 & $\ldots$ \\
\hline & 35654643 & 07-01-2011:12.06 & check ticket & Mike & 100 & $\ldots$ \\
\hline & 35654644 & 08-01-2011:14.43 & examine thoroughly & Sean & 400 & $\ldots$ \\
\hline & 35654645 & $09-01-2011: 12.02$ & decide & Sara & 200 & $\ldots$ \\
\hline & 35654647 & $12-01-2011: 15.44$ & reject request & Ellen & 200 & $\ldots$ \\
\hline$\cdots$ & $\ldots$ & $\ldots$ & $\ldots$ & $\ldots$ & $\ldots$ & $\ldots$ \\
\hline
\end{tabular}

Gambar 2. Contoh Event Log (sumber : (W.M.P. van der Aalst, 2011))

Event log terdiri dari sekumpulan case (atau sequenceltrace) dan dibuat menjadi suatu tabel khusus seperti yang tunjukan oleh Gambar 2. Setiap case dalam event log diidentifikasi secara unik oleh sebuah $i d$. Terlepas dari jenis analisis yang dilakukan pada proses mining, masing-masing event diberi sebuah ciri (case identifier) berupa case id yang menginformasikan case yang berkaitan dengan event tersebut dan sebuah label "activity" yang menjelaskan tindakan terkait. Dalam analisis process discovery juga dibutuhkan "timestamp" yang mendeskripsikan kapan peristiwa tersebut terjadi. Sedangkan dalam analisis lainnya dibutuhkan sebuah informasi tambahan yang relevan seperti aktor/sumber daya yang terkait terhadap proses tersebut. Oleh karena itu dibutuhkan label "resource".

\section{II.3 Petri Net}

Petri Net merupakan suatu perangkat untuk pemodelan dan menganalisis sistem sehingga dapat diperoleh informasi tentang struktur dan perilaku dinamik dari sistem yang di modelkan (Peterson, 1981). Petri Net dapat mendeskripsikan dengan jelas distribusi dan redistribusi energi yang terjadi pada sistem. Hasil analisis kemudian dijadikan referensi untuk memperbaiki sistem yang ada.

Petri Net menggunakan bahasa grafis dan matematis untuk pemodelan dan analisis sistem yang bersifat diskrit, di mana harga variabel-variabel sistem hanya berada pada dua keadaan seperti on atau off maupun aktif atau tidak aktif. Representatif grafis dari Petri Net membuat Petri Net banyak digunakan di berbagai bidang seperti kontrol proses, jaringan komputer, sistem antrian, dan lain-lain (Moody \& Antsaklis, 1998).

Petri Net dibentuk oleh place dan transisi yang dihubungkan dengan panah. Place yang digambarkan dengan lingkaran, merepresentasikan kondisi. Transisi yang digambarkan dengan kotak persegi panjang atau garis lurus, merepresentasikan event atau kejadian. Penandaan (marking) merupakan hubungan antara token dengan place. Token digambarkan dengan titik kecil, berpindah-pindah dari satu place ke place lain ketika terjadi pemicuan transisi (firing).

Petri Net merupakan sebuah struktur dinamik yang terdiri atas tiga komponen utama yang ditunjukkan oleh Tabel 1. Transisi akan aktif jika semua input place berisi token. Saat transisi ini terpatik (aktif) maka token akan berpindah dari place awal menuju place berikutnya sesuai dengan arc (arah panah).

Tabel 1. Komponen Petrinet

\begin{tabular}{|c|c|c|}
\hline Nama & Lambang & Keterangan \\
\hline Places & & $\begin{array}{l}\text { Merepresentasikan keadaan } \\
\text { sistem, dimana place dapat } \\
\text { menyimpan satu atau } \\
\text { beberapa token (ditunjukkan } \\
\text { sebagai titik hitam) }\end{array}$ \\
\hline
\end{tabular}

Nur Fitrianti Fahrudin

Jurnal Ilmiah Teknologi Informasi Terapan

Volume 6, No 2, 15 April 2020 


\begin{tabular}{cll}
\hline \hline Nama & Lambang & \multicolumn{2}{c}{ Keterangan } \\
\hline \hline Transitions & & $\begin{array}{l}\text { Satu set transisi (trasitions) } \\
\text { yang ditandai oleh sebuah } \\
\text { kotak yang berhubungan } \\
\text { terhadap suatu pekerjaan } \\
\text { atau sebuah aktifitas yang } \\
\text { dapat dieksekusi }\end{array}$ \\
\hline \hline Directed arcs & & $\begin{array}{l}\text { Setiap arcs hanya } \\
\text { menghubungkan place } \\
\text { dengan transition atau } \\
\text { transition dengan suatu } \\
\text { place }\end{array}$ \\
\hline \hline
\end{tabular}

Perilaku dinamik ditunjukkan aliran token pada jala serta diikuti dengan perubahan penandaan place. Aliran ini terjadi akibat proses pemicuan transisi yang memindahkan token dari satu place menuju place lainnya (Andriani, n.d.).

\section{AnAlisis dan Perancangan}

Terdapat empat tahapan yang perlu dilakukan untuk melakukan proses mining yaitu persiapan event log, inspeksi log, proses discovery dan conformance checking.

\section{a. Persiapan Log}

Langkah pertama yang perlu dilakukan adalah mengidentifikasi proses bisnis utama atau primary processes, yaitu proses end-to-end yang memberikan value kepada konsumen secara langsung. Setelah proses bisnis utama berhasil diidentifikasi, dilakukan pemodelan proses bisnis. Notasi yang dipilih untuk memodelkan proses bisnis pada tahap ini adalah BPMN (Business Process Model Notation). Model proses ini akan dimodelkan berdasarkan dokumen SOP yang dimiliki oleh perusahaan.

Setelah model selesai dibuat, selanjutnya adalah memastikan bahwa setiap aktifitas di dalam proses bisnis itu terekam dalam database yang terhubung dengan sistem informasi. Langkah kedua adalah mendapatkan Entity Relationship (ER) diagram atau class diagram yang terkait dengan proses bisnis utama. Diagram ER atau diagram class ini memperlihatkan hubungan antar tabel yang terkait dalam satu fungsionalitas/proses bisnis tertentu. Hal ini dilakukan mengingat jumlah tabel yang sangat banyak, sehingga kita perlu melakukan scoping. Diagram ini akan digunakan sebagai acuan dalam menentukan atribut-atribut untuk membangun sebuah event log.

Ada beberapa atribut yang menjadi standar dalam sebuah event $\log$ menurut (Wil M. P. van der Aalst,
2011) yaitu timeStamp, caseId, eventId, activity dan resource. Berdasarkan analisis yang dilakukan terhadap diagram ER, secara spesifik akan diidentifikasi nama atribut apa saja yang dibutuhkan. Setelah diketahui atribut yang dibutuhan untuk membuat sebuah event log, selanjutnya adalah melakukan query untuk mendapatkan data yang dibutuhkan. Untuk membangun event $\log$ penulis perlu melakukan query ke basis data yang terhubung ke dalam Sistem Informasi Percetakan Bandung, query dilakukan untuk mengekstraksi data sesuai dengan kebutuhan analisis. Hasil query dapat dilihat pada Tabel 2 .

Tabel 2. Event Log Percetakan Bandung

\begin{tabular}{|c|c|c|c|}
\hline caseld & eventld & activity & yyyy-MM-dd;hh:mm \\
\hline 1 & 1 & Order & 2017-11-30;10:00 \\
\hline 1 & 2 & Setting & 2017-12-02;10:00 \\
\hline 1 & 4 & Production_kbr & $2017-12-05 ; 16: 00$ \\
\hline 1 & 8 & Pengiriman & 2017-12-06;16:00 \\
\hline 2 & 1 & Order & 2017-11-30;09:00 \\
\hline 2 & 2 & Setting & 2017-11-30;10:00 \\
\hline 2 & 4 & Production_kbr & 2017-12-04;10:00 \\
\hline 2 & 6 & Finishing_kbr & $2017-12-06 ; 10: 00$ \\
\hline 2 & 8 & Pengiriman & $2017-12-08 ; 10: 00$ \\
\hline 3 & 1 & Order & 2017-11-30;10:00 \\
\hline 3 & 2 & Setting & $2017-12-02 ; 10: 00$ \\
\hline 3 & 5 & Production_pgr & $2017-12-06 ; 16: 00$ \\
\hline 3 & 8 & Pengiriman & $2017-12-07 ; 16: 00$ \\
\hline$\cdots$ & ... & $\ldots$ & $\ldots$ \\
\hline 30 & 1 & Order & $2017-11-30 ; 10: 00$ \\
\hline 30 & 2 & Setting & $2017-12-04 ; 10: 00$ \\
\hline 30 & 3 & Production_jkt & 2017-12-05;10:00 \\
\hline 30 & 6 & Finishing_kbr & 2017-12-13;15:00 \\
\hline 30 & 8 & Pengiriman & $2017-12-13 ; 16: 00$ \\
\hline
\end{tabular}

Nur Fitrianti Fahrudin

Jurnal Ilmiah Teknologi Informasi Terapan

Volume 6, No 2, 15 April 2020 
Hasil dari query, selanjutnya akan dieksport ke dalam format csv.

\section{b. Inspeksi Log}

Log Inspection menyediakan hasil analisis awal terhadap event log. Hasil analisis awal yang dihasilkan berupa informasi statistik mengenai jumlah case, jumlah event, distribusi jumlah case per jumlah event beserta jumlah kemunculannya. Penulis memanfaatkan hasil inspeksi log ini untuk melakukan prapemrosesan sebelum event log akhirnya di clustering.

Inspeksi log dihasilkan pada saat dokumen csv diubah formatnya ke dalam bentuk XES dengan menggunakan tools ProM. Berikut Gambar 3. merupakan informasi statistik yang dihasilkan dari proses inspeksi log.

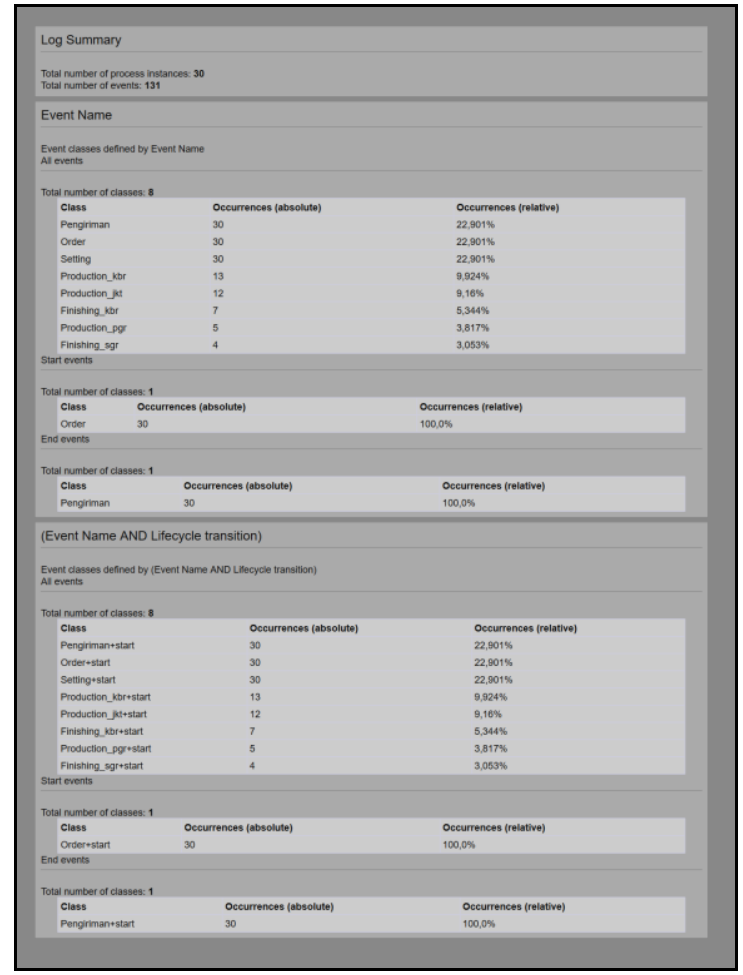

Gambar 3. Ringkasan Event Log Percetakan Bandung

\section{c. Proses Discovery}

Kumpulan dokumen csv yang telah dikonversi menjadi XES dapat langsung dimodelkan menggunakan teknik proses mining. Dalam tahap mining untuk menemukan pola proses bisnis yang terkandung didalam event log, penulis menggunakan tools yang telah disedikan oleh RapidMiner 8 dengan menambahkan fitur ProM kedalam Rapid Miner. Satu per satu dokumen akan dimodelkan menggunakan algoritma alpha miner, dimana model yang dihasilkan menggunakan notasi Petri Net. Selain menggunakan alpha miner penulis juga melakukan mining menggunakan tiga metode lainnya yang sama-sama dapat menghasilkan model Petri Net yaitu Integer Linear Programming miner (ILP), Heuristic Miner dan Inductive Miner.

Berikut ini pada Gambar 4 merupakan model proses bisnis dalam notasi Petri Net yang ditambang dari event log yang belum dikelompokan menggunakan algoritma Alpha Miner.

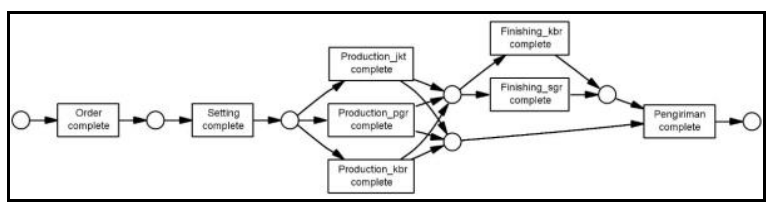

Gambar 4. Petri Net hasil discovery

Model proses ini merupakan gambaran dari keadaan saat ini yang ada dalam sebuah perusahaan. Model proses ini dibangun berdasarkan hasil mining yang dilakukan terhadap event $\log$ atau informasi yang tersimpan dalam Sistem Informasi. Dalam rangka mengevaluasi hasil mining dari automated process discovery ini

\section{d. Conformance checking}

Conformance Checking bertujuan untuk mendeteksi ketidaksesuaian antara model proses dan event log yang sesuai. Petri Net dan event log dikatakan "fit" atau "cocok" jika Petri Net dapat memainkan ulang (replay) setiap trace/sequence didalam event log. Dengan kata lain, Petri Net harus dapat menguraikan setiap event dalam sequence. Akan tetapi, nilai fitness yang baik tidak menyiratkan kesesuaian (conformance). Petri Net yang memiliki nilai fitness 1 belum tentu menghasilkan sebuah informasi yang bermakna.

Precision ini bertujuan untuk menangani masalah underfitting. Underfitting adalah kegagalan dalam mempelajari relasi yang terdapat dalam sebuah data.

Menurut (Wil M. P. van der Aalst, 2011) terdapat empat kriteria dalam mengukur kualitas dari model yang dihasilkan oleh proses mining yaitu :

- Fitness. Model yang dihasilkan harus memperlihatkan tindakan yang terdapat pada event log. Nilai fitness dihitung dengan 
menggambarkan seberapa baik kesesuaian antara model dengan event log. Teknik replay diuraikan untuk menghitung fitness sehingga menghasilkan nilai 0 untuk sangat buruk sampai 1 untuk sempurna. Teknik replay menggunakan sebuah event $\log$ dan model proses bisnis sebagai input. Berikut ini adalah Rumus 1 untuk menghitung nilai fitness :

fitness $(L, N)=$

$\frac{1}{2}\left(1-\frac{\sum_{\sigma \in L} L(\sigma) \times m_{N, \sigma}}{\sum_{\sigma \in L} L(\sigma) \times C_{N, \sigma}}\right)+\frac{1}{2}\left(1-\frac{\sum_{\sigma \in L} L(\sigma) \times r_{N, \sigma}}{\sum_{\sigma \in L} L(\sigma) \times p_{N, \sigma}}\right)$

Keterangan :

$\sum_{\sigma \in L} L(\sigma) \times m_{N, \sigma}:$

jumlah token yang hilang saat melakukan teknik replay, dimana $L(\sigma)$ adalah frekuensi jejak $\sigma$ dan $m_{N}, \sigma$ adalah jumlah token yang hilang untuk satu instance dari $\sigma$.

$$
\begin{array}{ll}
p & : \text { token yang dihasilkan } \\
c & : \text { token yang digunakan } \\
m & : \text { token yang hilang } \\
r & : \text { token yang tersisa }
\end{array}
$$

- Precision. Precision / Behavioral Appropriateness bertujuan untuk mengevaluasi seberapa tepat suatu model menggambarkan proses yang diamati. Precision mengevaluasi berapa banyak behavior yang diijinkan oleh model yang sebenarnya tidak pernah ada dalam event log. Model yang dihasilkan seharusnya tidak menampilkan tindakan yang tidak berhubungan dengan apa yang terdapat pada event log. Untuk menghitung precision dapat menggunakan Rumus 2.

$$
a_{B}^{l}=\frac{\left|S_{F}^{l} \cap S_{F}^{m}\right|}{2 *\left|S_{F}^{m}\right|}+\frac{\left|S_{P}^{l} \cap S_{P}^{m}\right|}{2 *\left|S_{P}^{m}\right|}
$$

Keterangan :

$S_{F}^{l}$ : jumlah relasi sometime follow pada event $\log$

$S_{F}^{m}$ : jumlah relasi sometime follow pada model

$S_{P}^{l}$ : jumlah relasi sometime precedes pada event log
$S_{P}^{m}$ : jumlah relasi sometime precedes pada model

- Generalization. Model yang dihasilkan harus men-generalisasi tindakan yang terdapat di dalam event log.

- Simplicity. Model yang ditemukan harus sesederhana mungkin.

Pada tahap ini pengujian dilakukan dengan menguji nilai fitness dan precision dari sebuah model proses yang telah dihasilkan oleh proses discovery. Berikut pada Tabel 3 adalah hasil pengujian yang dilakukan menggunaka empat buah metode.

Tabel 3. Hasil Pengujian

\begin{tabular}{ccccccccc}
\hline \hline \multicolumn{2}{c}{ Alpha } & \multicolumn{2}{c}{ ILP } & \multicolumn{2}{c}{ Inductive } & \multicolumn{2}{c}{ Heuristic } \\
\hline \hline $\boldsymbol{f}$ & $\boldsymbol{p}$ & $\boldsymbol{f}$ & $\boldsymbol{p}$ & $\boldsymbol{f}$ & $\boldsymbol{p}$ & $\boldsymbol{F}$ & $\boldsymbol{p}$ \\
\hline \hline $\mathbf{0 , 9}$ & 0,88 & 1 & 0,875 & 0.996 & 1 & 0,993 & 0,878 \\
\hline \hline
\end{tabular}

\section{KESIMPULAN DAN SARAN}

Berdasarkan kepada hasil pengujian metode inductive memiliki nilai fitness dan precision yang lebih tinggi jika dibandingkan dengan metode lainnya. Hal ini berarti metode inductive berhasil memetakan event log yang ada menjadi sebuah proses bisnis yang tepat dan sesuai. Hasil dari proses discovery inilah, evaluasi terhadap kinerja dari bisnis dapat dilakukan. Karena penggambaran proses bisnis ini dilakukan oleh komputer, hasilnya pun dapat dipastikan terbebas dari asumsi-asumsi. Pemodelan proses seperti ini juga memakan waktu yang relatif lebih cepat jika dibandingkan dengan melakukan analisis secara konvensional atau manual.

Proses mining sendiri sangat bergantung kepada event log, jika event log yang didapatkan atau diolah nantinya tidak merekam semua aktifitas proses bisnis yang terjadi dilapangan, maka hal ini akan mempengaruhi hasil dari proses discovery. Model yang dihasilkan oleh proses discovery menjadi tidak nyata karena terdapat banyak sekali proses yang tidak terekam. Oleh karena itu proses persiapan event log menjadi hal yang penting untuk memastikan bahwa semua proses terekam dalam sistem informasi.
Nur Fitrianti Fahrudin

Jurnal Ilmiah Teknologi Informasi Terapan

Volume 6, No 2, 15 April 2020 


\section{REFERENSI}

Andriani, E. (n.d.). Model Petri Net Dan Markov Chain. Retrieved March 5, 2018, from http://www.eviandriani.com/2012/01/modelpetri-net-dan-markov-chain.html

Daniel Minoli. (2008). Enterprise Architecture A to Z Frameworks, Business Process Modeling, SOA, and Infrastructure Technology. Auerbach Publications.

Gemini, C. (2007). Global CIO Survey 2007. IT Agility: Enabling Business Freedom.

Kenneth C. Laudon, \& Jane P. Laudon. (2013). essentials of management information systems.

Moody, J. O., \& Antsaklis, P. J. (1998). Supervisory Control of Discrete Event Systems Using Petri Nets. Norwell: Kluwer Academic Publishers.

Peterson, J. L. (1981). Petri Net Theory and the Modelling of Systems. Ney Jersey: Prentice Hall Inc.

Rose, K. (2005). Project Quality Management: Why, what and how. J. Ross Pub., 2005.

Suriadi, S., Andrews, R., ter Hofstede, A. H. M., \& Wynn, M. T. (2017). Event log imperfection patterns for process mining: Towards a systematic approach to cleaning event logs. Information Systems, 64, 132-150. https://doi.org/10.1016/j.is.2016.07.011

van der Aalst, W. (2016). How to get started with process mining? 1-6. Retrieved from http://wwwis.win.tue.nl/ wvdaalst/courses/howt ogetstartedwithprocessmining.pdf

van der Aalst, W. M. P. (2011). Process Mining. In Process Mining (Vol. https://doi.org/10.1007/978-3-642-19345-3

van der Aalst, W. M. P. (2016a). Process Mining. In Process Mining (Vol. https://doi.org/10.1007/978-3-642-19345-3

van der Aalst, W. M. P. (2016b). Process Mining. In Process Mining Data Science in Action Second Edition (2nd ed., pp. 30-34). https://doi.org/10.1007/978-3-662-49851-4

Veiga, G. M., \& Ferreira, D. R. (2010). Understanding spaghetti models with sequence clustering for ProM. Lecture Notes in Business Information Processing, 43 LNBIP, 92-103. https://doi.org/10.1007/978-3-642-12186-9_10

Vossen, G. (2012). The process mining manifesto An interview with Wil van der Aalst. Information Systems, 37(3), 288-290. https://doi.org/10.1016/j.is.2011.10.006

Wang, Z., Pan, S. L., Yang, T. H. O., \& Chou, T.-C. (2011). Evolving IT Organizational Identity as a Source of IT-enabled Enterprise Agility in China. Icis, 61(1), Paper 5. Retrieved from http://aisel.aisnet.org/icis2011/proceedings/issu es/5/
Nur Fitrianti Fahrudin

Jurnal Ilmiah Teknologi Informasi Terapan

Volume 6, No 2, 15 April 2020 